\title{
Fairness in the climate negotiations: what explains variation in parties' expressed conceptions?
}

\author{
Vegard Tørstad and Håkon Sælen \\ Published in Climate Policy
}

\section{Introduction}

In December 2015, parties to the United Nations Framework Convention on Climate Change (UNFCCC) reached a new climate agreement in Paris. The new agreement is largely a bottom-up framework, based on voluntary pledges of national climate policies with no common format. This structure marks a fundamental shift from the Kyoto Protocol, in which national commitments were internationally agreed and expressed in a common format.

The shift in structure from the Kyoto Protocol to the Paris Agreement partly results from a lack of consensus on fundamental burden-sharing principles (Breakey, 2016). The question of how to differentiate efforts fairly has always been central and controversial in UN climate negotiations. Since the UNFCCC's conception in 1992, parties have tried to agree on principles for deciding who are to contribute, and how much, to the mitigation efforts required to reach a global greenhouse gas emissions level defined as 'safe'. Three fairness principles have been commonly invoked and widely accepted by parties in the negotiations: Responsibility, Capability, and Rights (needs) (Underdal \& Wei, 2015). Aiming to elucidate how disputes over these three principles unfolded in the negotiations that led to the Paris Agreement, this article asks: (i) which parties support each of the three fairness principles? and (ii) which country attributes predict support for each principle?

The first question is addressed by using content analysis to count the references by each party and negotiating group to the three fairness principles in submissions presented to the Ad Hoc Working Group on the Durban Platform for Enhanced Action (ADP), the forum for negotiations leading up to the Paris Conference (2012-2015), resulting in a database of parties' fairness conceptions. The findings show that while many parties' fairness conceptions converge, the conceptions of certain major emitters strongly diverge. 
The second part of the analysis explores why parties have diverging fairness conceptions. Using the findings from the content analysis as dependent variables, it investigates which country characteristics determine support for different fairness principles. In contrast to much of the previous literature on the topic, it finds that the most consistent and powerful determinant is whether a country is included in Annex I to the UNFCCC, which lists 'developed' countries.

The binary Annex-division between 'developed' and 'developing' countries was the basis for differentiating obligations under the UNFCCC and the Kyoto Protocol. The Paris Agreement, by contrast, does not refer to this Annex, and instead establishes a process of selfdifferentiation in which countries define their own contributions. The dominant variable in explaining past divergences in fairness conceptions has thus been made less relevant. However, several paragraphs in the Paris Agreement refer to an undefined group of 'developed' countries, providing an opportunity for parties to engage the Annex-division to provide content to the term (Rajamani, 2016). The ongoing negotiations on implementing the Paris Agreement have already encountered 'roadblocks' that partially derive from how the Agreement resolved the issue of differentiation between 'developed' and 'developing' countries (IISD 2016a). As such, the results from this analysis appear relevant for understanding post-Paris negotiations dynamics as well.

This article is - to our knowledge - the first quantitative assessment of fairness conceptions in the recent negotiations leading to the Paris Agreement. It also differs from existing analyses of earlier negotiations in that it assesses parties' official positions rather than individuals' personal views or their perceptions of parties’ positions.

The next section provides the context for the analysis, presenting fairness in climate negotiations from both a historical and theoretical perspective. The subsequent two sections present the hypotheses tested and the methods for doing so. The results are then discussed, and finally, some concluding remarks are offered regarding implications for ongoing negotiations.

\section{Literature review and theoretical background}

This section provides a short historical overview of how the climate negotiations have dealt with fairness, and links this to theoretical literature on justice and fairness. Three fairness 
principles emerge as predominant, and each is discussed briefly. The section then asks why fairness matters in climate negotiations, and proposes that fairness conceptions can be understood as reflections of self-interest.

\section{Fairness provisions and their operationalisation in the climate negotiations}

Discussions over fairness have been central to climate negotiations at least since negotiations on the UNFCCC began in 1990 (see Bodansky, 1993). The UNFCCC’s (UN, 1992) Article 3 establishes a principle for distributing efforts fairly: the principle of 'common but differentiated responsibilities and respective capabilities’ (CBDR-RC)

Parties' responsibilities and capabilities were hence considered normatively relevant factors for differentiating mitigation burdens. Furthermore, the Convention operationalises CBDRRC by dividing the world into two broad strands. It defines which countries count as 'developed' through its Annex I, which originally listed 36 countries (later expanded to 43) that at the time were members of the OECD or in the process of transition to a market economy. Remaining countries were considered 'developing', and are commonly labelled 'non-Annex I'. This binary categorization constitutes the regime's cornerstone, although there are further sub-categories within each strand (Depledge, 2009). The subsequent Kyoto Protocol (UN, 1997) contained legally binding and country-specific, quantitative mitigation targets for Annex I parties only. Under the Convention and the Kyoto Protocol, non-Annex I countries had only qualitative commitments and were eligible for financial and technological support.

The clear-cut division between Annex I and non-Annex I parties - often referred to as the 'firewall' - has not been substantially updated since 1992, despite sustained pressure from Annex I parties to do so (Kallbekken, Sælen \& Underdal, 2014). The Convention created procedures for voluntary graduation to Annex I, but these have not been widely utilized (for details, see Depledge, 2009). Over the course of negotiations, the parties on each side of the 'firewall' have come to interpret the CBDR-RC principle differently. Generally, 'developing' countries have understood CBDR-RC to define responsibilities for having contributed to the climate problem, while 'developed' countries have instead emphasised capabilities to mitigate (Brunnée \& Streck, 2013). 


\section{Fairness principles in the climate negotiations}

Capability and Responsibility remain today as two of the three generally accepted fairness principles in the negotiations. Underdal and Wei (2015) assert that three different understandings of how the mitigation burden of greenhouse gases should be distributed fairly are frequently invoked and rarely disputed in the negotiations: Responsibility for damage caused, Capability to solve the problem, and Rights (needs). However, differences arise over how to interpret and weight them. Those differences are explored in this paper.

The three fairness principles are broad prescriptive categories that can be interpreted differently and specified into burden-sharing schemes in numerous ways. In this analysis, they are chosen as the dependent variables because they simultaneously correspond to the three basic fairness principles in the distributive justice tradition in philosophy (see Caney, 2006; Miller, 2013), they capture the most discussed notions of fairness in the environmental economics literature (see Kverndokk \& Rose, 2008), and they subsume most or all of the more specific 'equity principles' that are discussed in the literature on fairness in the climate negotiations (e.g. Dannenberg, Sturm \& Voigt, 2010; Lange, Vogt \& Ziegler, 2007; Ringius, Torvanger \& Underdal, 2002).

The IPCC’s fifth assessment report (Working Group 3) refers to three fairness principles in section 6.3.6.6 (Responsibility, Capability, and Equality) (Clarke et al., 2014), and an additional fourth principle in section 4.6.2 (Right to development) (Fleurbaey et al., 2014). As explained below, this analysis refers to both Equality and Right to development under the category Rights (needs). The paragraphs that follow briefly discuss the three fairness principles that are the subjects of this analysis, and some of their corresponding equity principles.

\section{Fairness as Responsibility}

The principle of Responsibility demands that a problem should be solved by the party that caused it. In the case of climate change, this simply means that polluters must somehow pay.

Responsibility encompasses two equity principles that are frequently invoked in the negotiations. The polluter-pays principle is the idea that costs and emission cuts related to climate change should be distributed proportionally to the share of an actor's current 
emissions (Ringius et al., 2002). The historical responsibility principle implies dividing responsibility in proportion to cumulative or past emissions, or in proportion to contributions to warming.

\section{Fairness as Capability}

The Capability principle emphasises that those who have the capacity to solve the problem have an imperative to do so. Because of the vast array of solutions to climate change, Capability is a multifaceted indicator. Compared with Responsibility, which is naturally linked to emissions, Capability provides for a larger number of defensible interpretations. Interpretations include (but are not limited to) the possibility to establish greenhouse gas 'sinks', innovation capacity, capacity to transform energy systems, and prospects for improving energy efficiency or for reducing energy usage (Kallbekken et al., 2014). The most common and universal operationalisation of capabilities is capacity to pay: the idea that burdens should be distributed in accordance with the parties' financial capacities, usually measured in GDP.

\section{Fairness as Rights (needs)}

The Rights (needs) principle broadly suggests that an actor is either entitled by right to enjoy a given amount of the good in question, or that it needs to be exempted from undertaking provisions. In the climate negotiations, the Rights (needs) principle appears frequently as the egalitarian principle - the idea that all humans have an equal right to emit the same amount of greenhouse gases (Lange, Löschel, Vogt \& Ziegler, 2010; Fleurbaey et al., 2014). While this principle is arguably the most persuasive 'on ethical grounds' (Paterson, 2001), it scores low on political feasibility because it entails large redistributions relative to the status quo. Closely related are the equity principles of 'right to development' (Fleurbaey et al., 2014), 'equal access to sustainable development', and 'poverty eradication'. These terms are employed to justify that 'developing' countries should be allowed to develop the same way as the industrialised ones have, with the implication that the mitigation burden would fall heavily or entirely on industrialised countries (Mattoo \& Subramanian, 2010).

\section{Why does fairness matter in climate negotiations?}

Normally, successful cases of multilateralism generate expectations of reciprocity among participants (see Keohane, 1986). For this reason, the literature suggests that multilateral 
agreements have the highest potential for both consensus and compliance if they are based on a common understanding of what fairness is (Ringius et al., 2002).

Generally, distributive fairness is relevant in situations characterised by 'moderate scarcity', meaning that everyone can expect to have a share in the allocation, but no one can expect to have all they desire (Rawls 1999). Moderate scarcity is the first of two preconditions for fairness discourse. The second is 'community' - a social system of continuing interaction (Franck, 1995).

Furthermore, fairness plays a particularly important role in the climate negotiations because powerful states are less able to coerce weaker states than they are in other policy areas, implying greater need for fostering a sense of legitimacy to achieve effective implementation and compliance (Young, 2014).

For these and other reasons, the empirical literature has often suggested that differing fairness conceptions among parties in the climate negotiations constitutes an obstacle to the creation of an ambitious and effective climate agreement (Hjerpe, Löfgren, Linnér \& Hennlock, 2011; Kesternich, Löschel \& Ziegler, 2014). Therefore, an answer to why such conceptions differ in the first place would be helpful to evaluate the prospects for reaching such an agreement.

\section{An interest-based understanding of fairness}

Various studies on fairness in negotiations have suggested that negotiators tend to invoke the fairness principles that best correspond with their own interests (Albin, 1993; Babcock \& Loewenstein, 1997; Lange et al., 2010; Underdal \& Wei, 2015). This dynamic can be understood through Brian Barry’s theory of justice as 'rational prudence':

Justice is simply rational prudence pursued in contexts where the cooperation (or at least its forbearance) of other people is a condition of our being able to get what we want. Justice is the name we give to the constraints on themselves that rational self-interested people would agree to as the minimum price that has to be paid in order to obtain the cooperation of others (Barry, 1989). 
This theory suggests that a party will invoke universal fairness principles in order to strengthen its bargaining power - and thereby promote its own interests - because in conflicts of interest, even argumentation that tries to justify self-interest must be based on some (commonly accepted) universalistic values in order to receive support from others (Elster, 1998; Risse, 2000).

The hypothesis that fairness conceptions in climate negotiations are determined by selfinterest has been directly or indirectly addressed in extant empirical studies. Hjerpe et al. (2011) surveyed fairness preferences among delegates and observers at COP15 in 2009, measuring support/opposition rates for eight equity principles. In line with national selfinterest, EU delegates expressed less support than others for a principle of historical responsibility, while G77+China delegates expressed stronger support than others for a principle of needs. Low participation by state delegates precluded systematic assessment of differences between parties.

Kesternich et al. (2014) asked negotiators and observers at COP16 and COP17 to assign weights to different burden-sharing rules. Positions on the polluter-pays rule can be explained by differences in economic development, in line with the self-interest hypothesis. On the ability-to-pay rule, differences across parties appear less stark. Notably, negotiators from all major regions indicate some willingness to support several fairness principles.

Most closely related to the current analysis are two studies, both based on a 2004 survey of people involved in climate negotiations, that measure support for different burden-sharing rules. Lange et al. (2007) regress respondents' support for these rules on, inter alia, characteristics of the respondents' home country. The study finds that variations in support is partly compatible with self-interest. As expected, respondents from countries with high GDP per capita were less supportive of both the ability-to-pay and polluter-pays rules than others. However, respondents from G77+China countries are less supportive than others of the egalitarian rule, an apparent departure from self-interest. The same survey also elicited respondents' perceptions of how strongly the different rules were supported by the EU, the USA, Russia, and the G77+China. Lange et al. (2010) compare these responses with abatement costs implied by different rules for the four regions. They find that abatement costs explain perceived support for the different equity rules by these regions, except by the G77+China, in which case no link can be established. 


\section{Hypotheses}

An interest-based explanation of fairness conceptions suggests that parties in the climate negotiations will invoke the fairness principles that are most beneficial for themselves in terms of costs and benefits. To minimise their own costs, countries with high current or historical greenhouse gas emissions should, according to this logic, not express preference for the Responsibility principle, and countries with high capacity to pay should not support the Capability principle. In line with the reasoning in Lange et al. (2007), the first three hypotheses are therefore:

$\mathrm{H}_{1}$ : High current greenhouse gas emissions decrease the probability of supporting the Responsibility principle.

$\mathrm{H}_{2}$ : High historical greenhouse gas emissions decrease the probability of supporting the Responsibility principle.

$\mathrm{H}_{3}$ : High capacity to pay (GDP per capita) decreases the probability of supporting the Capability principle.

The above three hypotheses follow straight-forwardly from a theory of self-interest. Additionally, however, the history of UNFCCC climate negotiations suggests that whether a country is classified as 'developed' might have an independent effect from its actual capacity and responsibility - which means that a variable for Annex I membership should be added to the analysis.

Castro et al. (2014) find that the Annex division strongly influences negotiation behaviour, as non-Annex I countries have an incentive to jointly lobby for the continuation of status quo. Following the previously discussed argumentation of Brunnée \& Streck (2013), who proposed that 'developing' countries tend to emphasise responsibilities and 'developed' countries to support capabilities in questions of burdens-sharing, it is expected that Annex I parties will prefer the Capability principle, while non-Annex I parties will prefer the Responsibility principle. In general, Capability is a more dynamic concept than Responsibility, providing a 
stronger rationale for dismissing the Annex division. In addition, as discussed above, Capability can encompass a broader range of interpretations than Responsibility can, making quantification less straightforward. Annex I countries that score high on most traditional indicators of both Responsibility and Capability might therefore prefer Capability to Responsibility in order to avoid quantification completely. They can also argue that nontraditional indicators such as abatement costs and domestic co-benefits - on which they score relatively favourably - are relevant for Capability (see CAIT, 2015; Kallbekken et al., 2014). As discussed above, Rights (needs) can be invoked to support exemption for 'developing' countries and for imposing large burdens on 'developed' countries, implying it is a principle that should be favoured by non-Annex I countries.

H4: Having 'Annex I’ status decreases the probability of supporting the Responsibility principle.

H5: Having 'Annex I’ status increases the probability of supporting the Capability principle.

$\mathrm{H}_{6}$ : Having 'Annex I’ status decreases the probability of supporting the Rights (needs) principle.

Lastly, Sprinz \& Vaahtoranta (1994) have argued that vulnerability to climate change should be included in a self-interest based explanation of environmental policy. To minimise damages due to climate change, vulnerable countries can be expected to focus on ambition rather than on the distribution of efforts. However, as a means to secure finance for dealing with damages, the Responsibility principle may provide particular leverage - following the logic that those responsible for causing the damages should pay.

$\mathrm{H}_{7}$ : Vulnerability to climate change increases the probability of supporting the Responsibility principle.

\section{Methods}

The two research questions (i) which fairness principles do parties support? and (ii) which country characteristics predict support for each principle? entail a two-step empirical analysis. First, content analysis is used to map countries' references to fairness principles. Second, regression analysis is used to investigate which country characteristics explain the distribution 
of references across countries. The dependent variables are the number of references to Responsibility, Capability, and Rights (needs). The analysis does not distinguish between references to sub-principles within each of those three, for example, between current and historical Responsibility.

\section{Content analysis}

Parties’ support for fairness principles is inferred through a manual content analysis of position documents. The systematic analysis of such documents is an efficient means to reveal relevant information about the policy positions of their authors (Laver, Benoit \& Garry, 2003), and previous empirical studies have indeed confirmed this approach as fruitful for analysing positions in the climate negotiations (see especially Genovese, 2014; Torvanger \& Godal, 1999; Weiler, 2012).

Content analysis is a research method for systematic and quantitative description of the manifest content of communication (Berelson, 1952). Ideally, it is a deductive, systematic, and objective technique for making replicable and valid inferences from texts (Hardy, Harley \& Phillips, 2004; Krippendorff, 2013). The deductive aspect is in this case provided by the theoretical framework on fairness principles. Objectivity and reliability are ensured by the definition of precise analytical categories based on the fairness principles, which are used to systematically include or exclude content from the analysis. The fairness categories and coding rules are defined in a coding book (see online appendix i).

Human and automated computer-assisted coding are the two common approaches for coding positions from policy documents (Laver et al., 2003). This analysis is based on the former approach, primarily due to its validity merits. Firstly, hand coding permits the working back and forth between the data material and the coding book, enabling a reflective approach concerning the classification of the coding unit, as suggested by Hardy et al. (2004). Practically, this inductive feature of our research design ensures that the analysis is based on fairness principles as they are invoked by the actors themselves, instead of a purely deductive approach where different fairness principles are defined by the literature and subsequently proposed to the actors in surveys or interviews. Secondly, manual content analysis reduces 'noise' by ensuring that only the coding units located in sections and documents directly 
related to the research question are coded. ${ }^{1}$ On the downside, manual coding is always less reliable than computer-assisted coding. The reliability of this analysis depends largely upon the formulation of the coding book, which must be exhaustive and mutually exclusive. The different operationalisations of fairness principles in the coding book are specified as precisely as possible in order to ensure that these criteria are met. Additionally, a simple form of automated content analysis (a dictionary method) is used to cross-validate the results ex post. An example of a coded submission is provided in online appendix vi.

The document corpus of this analysis consists of parties' written proposals to the ADP. The ADP held its first meeting in 2012, and its mandate was fulfilled when it transmitted a draft text of the Paris Agreement to the Conference of the Parties in December 2015. There are three types of position documents that were presented to the ADP: submissions, statements, and intended nationally determined contributions (INDCs). In this analysis, the submissions and INDCs are coded. ${ }^{2}$ Submissions are written proposals submitted prior to or during the negotiation sessions, while INDCs are the nationally determined climate actions that the parties plan to undertake. The corpus consists of all the submissions and INDCs over the duration of the ADP (2012-2015), amounting to a total of 298 position documents.

\section{Regression analysis}

The content analysis provides the frequency with which the parties refer to the three fairness principles in the position documents. To capture how strongly a party supports a principle compared to the two other principles, relative frequencies are used as dependent variables in the analysis; that is, the number of references to a principle divided by the number of references to all three principles. Due to this form of the dependent variables, we use the beta regression model, which is developed specifically for modelling proportions. Methodological details are provided in online appendix ii.

The independent variables were selected to test the hypotheses presented above. In other words, these are the variables that the literature review gave reason to believe might affect

\footnotetext{
${ }^{1}$ For example, this approach allows for excluding 'negative' references to a fairness principle.

${ }^{2}$ Statements are oral declarations which are sometimes also submitted in writing. Because the complete set of statements is not available, including the available subset would mean that results would be affected by variation in the rates at which parties submit statements in writing. Furthermore, because core positions and principles are covered in submissions, statements tend to either repeat from submissions, or deal with more procedural matters.
} 
fairness conceptions. They are listed in Table 1 along with the data sources. Groups are assigned the mean of their members' values on the independent variables.

[Insert Table 1: Independent variables in regression analysis with data sources]

\section{Results and discussion}

This section first presents descriptive results from the content analysis of submissions and INDCs. Thereafter, a regression analysis that seeks to account for the variation among parties in the descriptive results is presented and discussed.

\section{Results of content analysis}

A total of 160 parties and 11 negotiation groups ${ }^{3}$ submitted a minimum of one of the two types of position documents throughout the ADP negotiations, referring 1,799 times in total to the three fairness principles. A complete overview of all the fairness references is presented in online appendix iii.

Overall, non-Annex I parties refer more frequently to fairness than Annex I parties. Of the 10 actors that have most fairness references per negotiation document, only Switzerland is from the Annex I side of the 'firewall', as shown in Table $2 .{ }^{4}$ Among the parties that have the highest frequency of fairness references are Brazil, China, India, and the Like-Minded Developing Countries on Climate Change (LMDC) group. ${ }^{5}$ It appears, therefore, that 'developing' countries are more concerned with fairness than 'developed’ ones.

[Insert table 2: Parties with high frequencies of fairness references]

This result is not very surprising, as ‘developing’ countries are in general more inclined towards a burden-sharing approach than 'developed' countries. Furthermore, given that the UNFCCC is ‘unabashedly favourable to developing countries' (Rajamani, 2016, p. 506), these countries have good reason for referring to its principles and provisions. Many of their fairness references therefore allude directly to the UNFCCC. This finding also corresponds

\footnotetext{
${ }^{3}$ The EU negotiates on behalf of 28 parties, but is here counted as a negotiation group.

${ }^{4}$ Only actors that have submitted two or more position documents are included in the list.

${ }^{5}$ Online appendix iv lists the various members of the different groups.
} 
well with a survey analysis conducted by Lange et al. (2007), which finds that 'equity issues are seen as more important by individuals from G77/China countries’ (Lange et al., 2007).

\section{Clashing fairness conceptions}

Looking at how each party distributes its references to the three principles, two findings stand out. Firstly, there are many moderate parties. The African group, the Asociación Independiente de Latinoamérica y el Caribe (AILAC), the Alliance of Small Island States (AOSIS), the Environmental Integrity Group (EIG), the EU, Indonesia, Japan, Norway, and New Zealand are all 'moderate', in the sense that they support more than one fairness principle. Many of these distribute their fairness references roughly evenly between Responsibility and Capability, which seem to be the most widely accepted principles in the negotiation. This finding is in line with previous empirical analyses of the topic, most notably Hjerpe et al. (2011) and Kesternich et al. (2014). The tendency of distributing references to several fairness principles might be interpreted as good news for the prospects of reaching a common conception of fairness.

The bad news, however, is that fairness conceptions among the major emitters are polarised. The content analysis suggests that finding compromise between Australia, Canada, the United States, and Russia, on the one hand, and Brazil, China, India, LMDC and Saudi Arabia, on the other, can prove to be difficult. These parties are extremes on each side of the fairness spectrum. Australia, the United States, and Russia all refer to Capability in more than $75 \%$ of their references, while China, India, LMDC and Saudi Arabia devote the majority of their references to Responsibility, and also refer considerably more often to Rights (needs) than the former group does. The actors with the strongest preference for each principle are listed in online appendix $\mathrm{v}$.

\section{Results of regression analysis}

The second research question asks which country characteristics explain variation in fairness conceptions. Through regression analysis, this section investigates the effect of a set of country characteristics on parties' and negotiation groups' expressed relative support for the three fairness principles, ${ }^{6}$ thereby testing the hypothesis presented above. Three beta regression models - one with each fairness principle as the dependent variable - yield the

\footnotetext{
${ }^{6}$ For negotiation groups, the aggregated mean values of their members' characteristics are used.
} 
results presented in Table 3. Hypothesised relationships are denoted next to the corresponding coefficients, showing which hypotheses are supported. All the statistically significant coefficients are in line with the hypotheses, but not all the hypothesised relationships turn out to be significant. Each hypothesis is now discussed chronologically.

[Insert Table 3: Results from the regression analysis]

The first hypothesis, that Current emissions decrease the probability of supporting Responsibility, finds support. In contrast, the corresponding hypothesis $\left(\mathrm{H}_{2}\right)$ for Historical emissions is not supported. One reason may be that Historical emissions are correlated with both Current emissions and Annex I, so that it is difficult to estimate their isolated effect ${ }^{7}$. The third hypothesis, that Capacity to pay decreases the probability of supporting Capability, is not supported either. On the other hand, Capacity to pay increases the probability of supporting Responsibility. Because support for principles are measured in relative terms, that implies that high Capacity to pay decreases the probability of supporting Capability relative to Responsibility, other things being equal, in line with the overarching self-interest theory. Hypotheses 4, 5, and 6 concern the effect of Annex I membership. As hypothesised, such membership increases probability of supporting Capability and reduces the probability of supporting Rights (needs), while no significant effect is found on Responsibility. Annex I member is the only variable with significant effects on two principles, and it is the only significant predictor of support for Capability and Rights. For these two reasons, it emerges as the dominant variable overall. Finally, the significant coefficient for Vulnerability supports $\mathrm{H}_{7}$ that victims emphasise placing responsibility for the damages they suffer.

Two robustness tests were performed. First, an ordinary least squares regression was run with the same variables as the beta model. While this standard model is not the correct specification in this case, it provides a useful benchmark. Second, two additional control variables - democracy level (Freedom House, 2015) and petroleum rents (World Bank, 2013) - were introduced to the beta model, one-by-one and in combination. These variables may influence negotiation strategy (Bailer, 2012), but are not included in the main model due to the lack of hypotheses about their relationship with fairness conceptions. Both robustness

\footnotetext{
${ }^{7}$ However, omitting Current emissions and Annex I does not make Historical emissions significant.
} 
tests leave the main results unchanged: the same coefficients are significant, with the same signs. Furthermore, the coefficients for the control variables are not significant. Hence, the results seem robust to different model specifications.

\section{Discussion of regression results}

The empirical analysis shows that while factors commonly thought to influence self-interestbased environmental policy, such as vulnerability to climate change and greenhouse gas emissions (see Sprinz \& Vaahtoranta, 1994), do affect fairness conceptions in the climate negotiations, the dominant factor in determining fairness conceptions is the Annex variable. Controlling for other effects, the 'firewall' between the 'developed' and 'developing' countries is in itself an important factor for determining which fairness principles the parties prefer. How can this result be explained?

First, the Annex division is an important determinant of self-interest in the negotiations, being in itself a differentiation scheme with Annex I status linked to obligation and non-Annex I status to privileges (Castro et al., 2014). Hence, non-Annex I countries would benefit from the scheme's continuation and Annex I countries from its removal. Annex I countries have an incentive to emphasise countries' capabilities, the distribution of which has changed significantly since the Annex was written. Many parties (e.g., China, Singapore, Qatar, Saudi Arabia) that were classified as 'developing' in 1990 have outgrown many Annex I countries in terms of GDP per capita and other economic indicators.

On the other hand, non-Annex I countries can use the Rights (needs) principle to defend the 'firewall'. The most frequently invoked principle is the right to (socio-economic) development, implying that all countries should be allowed to follow a development trajectory similar to that of countries that developed early. Therefore, 'developed' countries must reduce emissions enough to leave a sufficient share of the carbon budget to 'developing' countries. This standpoint has been emphasised by India ${ }^{8}$ and Saudi Arabia among others.

Second, the dominance of Annex I status is likely corroborated by the coordination of negotiation positions in groups. Even though Annex I was expected to be important, one

\footnotetext{
${ }^{8}$ See for example Modi (2015).
} 
would still expect the other variables to have some effect after controlling for the Annex affiliation. For example, within the non-Annex I group, countries with high GDP per capita have the strongest incentive to oppose Capability as a fairness principle. The lack of explanatory power of these other variables may result from group dynamics on the two sides of the 'firewall' muting individual countries' incentives. In multilateral negotiations, group coordination is often important for developing individual actors' negotiation positions, often with the aim of generating leverage (see, e.g., Goldsmith \& Posner, 2005). When parties coordinate their positions, weak parties are susceptible to persuasion by powerful ones. This can lead weak parties to invoke principles that apparently contradict their self-interest. An illustrative example is the G77 group, whose membership consists of most non-Annex I countries. ${ }^{9}$ For the G77 it is collectively rational to support the 'firewall', and therefore to converge on fairness principles that support this objective. The G77 operates in and across multiple policy domains, so a weak member state may be persuaded to support a certain fairness conception in the climate negotiations because it wants G77 support in other domains.

The significance of the Annex variable is therefore compatible with the definition of justice as rational prudence: the parties invoke fairness principles strictly with the goal of advancing their own interests. This finding lends support to previous studies that have pointed to a tendency of self-interested fairness conceptions among climate negotiators (Hjerpe et al., 2011; Lange et al., 2010). However, in addition to self-interest-based reasons for acting collectively, it should be pointed out that unity in the G77 is also based on shared identities, narratives, and histories. Najam (2005) describes the group as 'a collective of countries that consider themselves to have been disempowered, marginalised and disenfranchised by the international system', and notes that their sense of collectivity is resilient to intra-group interest differences in the climate negotiations. Notably, the G77 has acted in a less united manner in negotiations on the Paris Agreement than they did in Kyoto negotiations, and certain groups of 'developing' countries have argued for 'shared responsibility across the North-South divide’ (Blaxekjær \& Nielsen 2015), including the groups that this paper places in the 'moderate' category (AILAC, African group, and AOSIS). However, while intra-G77

\footnotetext{
${ }^{9}$ For exceptions, see Depledge, 2009, pp. 275-276.
} 
differences have increased, the analysis conducted in this paper indicates that they are still dominated by the differences between the G77 and Annex I countries.

\section{Concluding remarks}

Disagreement over how to distribute mitigation costs plays a prominent role in international climate negotiations. Three understandings of what a fair burden-sharing scheme entails have frequently been invoked in the negotiations: Responsibility, Capability, and Rights (needs). This paper has investigated which country characteristics predict relative support for the three fairness principles, using a content analysis of submissions to the negotiations on the Paris Agreement. It tested a range of hypotheses derived from the assumption that expressed fairness conceptions are driven by self-interest.

The analysis showed that several factors often regarded as important to parties' self-interest such as historical emissions and capacity to pay - are not the primary determinants of fairness conceptions in the climate negotiations. Instead, whether a country is listed in 'Annex I' of the UNFCCC - that is, whether it is classified as 'developed' or 'developing' - is the strongest predictor. This finding indicates that the Annex division has profoundly shaped which fairness conceptions different parties support. An important explanation for this is that Annex I is in the Convention linked to obligations, while non-Annex I is linked to privileges (Castro et al., 2014), which means that non-Annex I countries benefit from the scheme’s continuation and Annex I countries from its removal. Therefore, the significance of the Annex variable is compatible with the assumption that parties invoke fairness principles with the goal of advancing their own interests.

In this light, it is notable that the Paris Agreement omits any reference to Annex I of the UNFCCC. Because the Annex division has been the clearest obstacle to convergence on fairness principles, the Agreement apparently resolves a fundamental tension in the negotiations. This development can be seen as a victory for the Annex I parties. Annex I and non-Annex I countries alike are now obliged to submit nationally determined contributions (NDCs) every five years. Burden-sharing will result from countries’ domestic decisions, rather than from international negotiations - a process termed 'self-differentiation'. In this process, parties are requested to justify their own contribution as 'fair and ambitious' (UNFCCC, 2015, decision no. 27). 
Another key element of the Paris Agreement is the 'global stocktake', which will assess collective progress every five years 'in light of equity' (UNFCCC, 2015, Article 14). The terms 'collective' and 'equity' will be challenging to square, as distributive fairness is inherently about comparing individual efforts. A skilfully crafted compromise will be required for the process to meaningfully include fairness considerations while avoiding finger-pointing. To achieve this, it is useful to note that the stocktake need not to take a single, authoritative position on what fairness is in order to drive up ambition (Breakey, 2016). A more flexible and pragmatic approach would be to link the process to parties' own fairness concepts as presented in their NDCs.

Generally, the finding that fairness-considerations are shaped by self-interest implies it will be difficult to achieve the kind of 'moral dialogue' envisioned by Breakey (2015) that leads parties to change their standpoints, as opposed to self-interested negotiations that can at best result in compromises. In light of this paper's finding, it is unsurprising that every fairnessrelated phrase in the Paris Agreement resulted from a carefully crafted compromise (Rajamani, 2016). The text contains multiple references to 'developed' versus 'developing' (or 'other') countries, leaving the door open for continued differentiation between the two groups in various areas - although the categorisation of countries is less clearly defined than in Annex I. Hence, the simpler, more binary distinction defined by the 1992 Convention has been replaced by a more subtle and ambiguous differentiation scheme (Dimitrov, 2016). In 2018, parties are to agree on a 'rulebook' for the Agreement. These seemingly technical discussions have already encountered 'roadblocks' that partially derive from how the Agreement resolved the issue of differentiation between 'developed' and 'developing' countries (IISD 2016b). It therefore appears that negotiators will have to continue to deal with this issue, even though it may take on a new dynamic now that the Annex I division has less force. In doing so, this paper suggests that looking for pragmatic solutions tailored to each substantive agenda point will be more fruitful than discussions at the level of fairness principles aiming for one overarching solution. Arguably, such a transition from principles to pragmatism already took place in the Paris Agreement (Rajamani, 2016).

\section{References}

Albin, C. (1993). The role of fairness in negotiations. Negotiations Journal, 9(3), 223-244. 
Babcock, L. \& Loewenstein, G. (1997). Explaining bargaining impasse: The role of selfserving biases. The Journal of Economic Perspectives, 11, 109-126.

Bailer, S. (2012). Strategy in the climate change negotiations: do democracies negotiate differently? Climate Policy, 12(5), 534-551.

Barry, B. (1989). Theories of justice. Berkeley: University of California Press.

Berelson, B. (1952). Content analysis in communication research. New York, NY: Free Press.

Blaxekjær, L.Ø. \& Nielsen, T.D. (2015). Mapping the narrative positions of new political groups under the UNFCCC. Climate Policy, 15(6), 751-766.

Bodansky, D. (1993). The United Nations Framework Convention on Climate Change: A Commentary. Yale Journal of International Law, 18(2), 451-558.

Breakey, H. (2015). COP20's Ethical Fallout: The Perils of Principles Without Dialogue. Climate Policy, 18(2), 156-169.

Breakey, H. (2016). Fairness on the agenda as UN begins job of strengthening the Paris climate deal. The Conversation. Retrieved from http://theconversation.com/fairnesson-the-agenda-as-un-begins-job-of-strengthening-the-paris-climate-deal-58789 [Last access: 20.12.2016].

Brunnée, J. \& Streck, C. (2013). The UNFCCC as a negotiation forum: Towards common but more differentiated responsibilities. Climate Policy, 13(5), 589-607.

CAIT (2015). Climate data explorer. Washington, DC: World Resources Institute. Retrieved from http://cait.wri.org [Last access: 24.12.2016].

Caney, S. (2006). Cosmopolitan Justice, Responsibility, and Global Climate Change. Leiden Journal of International Law, 18(4), 747-775.

Carlsson, F., Kataria, M., Krupnick, A., Lampi, E., Löfgren, A., Qin, P., Sterner, T. \& Chung, S. (2013). A Fair Share - Burden-Sharing Preferences in the United States and China. Resource and Energy Economics, 35(1), 1-17.

Castro, P., Hörnlein, L. \& Michaelowa, K. (2014). Constructed peer groups and path dependence in international organizations: The case of the international climate change negotiations. Global Environmental Change, 25, 109-120.

Clarke L., Jiang, K., Akimoto, K., Babiker, M., Blanford, G., Fisher-Vanden, K., ... van Vuuren, D.P. (2014): Assessing Transformation Pathways. In Edenhofer, O., PichsMadruga, R., Sokona, Y., Farahani, E., Kadner, S., Seyboth, K. .. Minx, J.C. (eds.), Climate Change 2014: Mitigation of Climate Change. Contribution of Working Group III to the Fifth Assessment Report of the Intergovernmental Panel on Climate Change 
(pp. 414-510). Cambridge, United Kingdom and New York, NY: Cambridge University Press.

Dannenberg, A., Sturm, B., \& Vogt, C. (2010). Do equity preferences matter for climate negotiators? An experimental investigation. Environmental and Resource Economics, 47(1), 91-109.

Dimitrov, R.S. (2016). The Paris Agreement on climate change: Behind closed doors. Global Environmental Politics, 16(3), 1-11.

Depledge, J. (2009). The road less travelled: difficulties in moving between annexes in the climate change regime. Climate Policy, 9(3), 273-287.

Elster, J. (1998). Introduction. In Elster, J. (ed.). Deliberative democracy. Cambridge: Cambridge University Press.

Fleurbaey, M., Kartha, S., Bolwig, S., Chee, Y.L., Chen, Y., Corbera, E., ... Sagar, A.D. (2014). Sustainable Development and Equity. In Edenhofer, O., Pichs-Madruga, R, Sokona, Y., Farahani, E., Kadner, S., Seyboth, K. ... Minx, J.C. (eds.). Climate Change 2014: Mitigation of Climate Change. Contribution of Working Group III to the Fifth Assessment Report of the Intergovernmental Panel on Climate Change (pp. 283-350). Cambridge, United Kingdom and New York, NY: Cambridge University Press.

Franck, T. (1995). Fairness in international law and institutions. New York, NY: Oxford University Press.

Freedom House (2016). Freedom in the World 2015. Retrieved from https://freedomhouse.org/sites/default/files/01152015_FIW_2015_final.pdf [Last access: 11.1.2017].

Genovese, F. (2014). States' interests at international climate negotiations: new measures of bargaining positions. Environmental Politics, 23(4), 610-631.

Global Carbon Project (2014). Fossil fuel and cement emissions 2013. Retrieved from Global Carbon Project: http://www.globalcarbonatlas.org/?q=en/emissions [Last access: 24.12.2016].

Goldsmith, J. \& Posner, E. (2005). The limits of international law. Oxford: Oxford University Press.

Hardy, C., Harley, B. \& Phillips, N. (2004). Discourse analysis and content analysis: Two solitudes? Qualitative Methods, 2(1), 19-22. 
Hjerpe, M., Löfgren Å., Linnér, B. \& Hennlock, M. (2011). Common ground for effort sharing? Preferred principles for distributing climate mitigation efforts. Working Paper in Economics No. 491, University of Gothenburg.

IISD (2016a). Summary of the Marrakech climate change conference: 7-19 November 2016. Earth Negotiations Bulletin, 12(676).

IISD (2016b). Summary of the Bonn climate change conference: 16-26 May 2016. Earth Negotiations Bulletin, 12(689).

Kallbekken, S., Sælen, H. \& Underdal, A. (2014). Equity and spectrum of mitigation commitments in the 2015 agreement. NOAK Report no.559 to the Nordic Council of Ministers. Retrieved from: http://norden.divaportal.org/smash/get/diva2:710898/FULLTEXT01.pdf [Last access: 24.12.2016].

Keohane, R. (1986). Reciprocity in international relations. International Organization, 40(1), $1-27$.

Kesternich, M., Löschel, A. \& Ziegler, A. (2014). Negotiating Weights for Burden Sharing Rules among Heterogeneous Parties: Empirical Evidence from a Survey among Delegates in International Climate Negotiations. ZEW Discussion Paper Series No. 14-031.

Krippendorff, K. (2013). Content analysis: An introduction to its methodology. Third edition. Los Angeles, CA: SAGE.

Kverndokk, S. \& Rose, A. (2008). Equity and Justice in Global Warming Policy. International Review of Environmental and Resource Economics, 2, 135-176.

Lange, A., Vogt, C. \& Ziegler, A. (2007). On the importance of equity in international climate policy: An empirical analysis. Energy Economics, 29(3), 545-562.

Lange, A., Löschel, A., Vogt, A. \& Ziegler, A. (2010). On the self-interested use of equity in international climate negotiations. European Economic Review, 54(3), 359-375.

Laver, M., Benoit, K. \& Gerry, J. (2003). Extracting Policy Positions from Political Texts Using Words as Data. The American Political Science Review, 97(2), 311-331.

Mattoo, A. \& Subramanian, A. (2010). Equity in climate change: An analytical review. Retrieved from the World Bank: http://elibrary.worldbank.org/doi/abs/10.1596/1813_ 9450-5383 [Last access: 24.12.2016].

Miller, D. (2013). Justice for Earthlings. Essays in Political Philosophy. Cambridge: Cambridge University Press. 
Modi, M. (2015, November 29). The rich world must take greater responsibility for climate change. Financial Times. Retrieved from: https://www.ft.com/content/03a251c695f7-11e5-9228-87e603d47bdc [Last access: 23.12.2016].

Najam, A. (2005). Developing countries and global environmental governance: From contestation to participation to engagement. International Environmental Agreements: Politics, Law and Economics, 5(3), 303-321.

ND-GAIN (Notre Dame Global Adaptation Index) (2015). Vulnerability Scores. Retrieved from ND-GAIN: http://index.gain.org/ranking/vulnerability [Last access: 11.12.2016].

Paterson, M. (2001). Principles of justice in the context of global climate change. Ch.6 in Luterbacher, U. \& Sprinz, D. (eds.): International relations and global climate change. Cambridge, MA: The MIT Press.

Rajamani, L. (2016). Ambition and differentiation in the 2015 Paris Agreement: interpretative possibilities and underlying politics. International and Comparative Law Quarterly, 65, 493-514.

Rawls, J. (1999). A theory of justice. Revised edition. Cambridge, MA: Harvard University Press.Ringius, L., Torvanger, A. \& Underdal, A. (2002). Burden sharing and fairness principles in international climate policy. International Environmental Agreements: Politics, Law and Economics, 2(1), 1-22.

Risse, T. (2000). 'Let’s Argue!’: Communicative action in world politics. International Organization, 54(1), 1-39.

Sprinz, D. \& Vaahtoranta, T. (1994). The interest-based explanation of international environmental policy. International Organization, 48(1), 77-105.

Torvanger, A. \& Godal, O. (1999). A survey of differentiation methods for national greenhouse gas reduction targets. CICERO Report no.5. Retrieved from: https://www.duo.uio.no/bitstream/handle/10852/32738/108.pdf?sequence=1 [Last access: 4.1.2017].

UN (1992). United Nations Framework Convention on Climate Change. Retrieved from UNFCCC: http://unfccc.int/files/essential_background/background_publications_htmlpdf/applicat ion/pdf/conveng.pdf [Last access: 23.12.2016].

UN (1997). Kyoto Protocol. Retrieved from UNFCCC: http://unfccc.int/kyoto_protocol/items/2830.php [Last access: 24.12.2016].

Underdal, A. \& Wei, T. (2015). Distributive fairness: A mutual recognition approach. Environmental Science \& Policy, 51, 35-44. 
UNFCCC (1996). Strengthening the commitments in Article 4.2(A) and (B) Quantified emission limitation and reduction within specified time-frames.

FCCC/AGBM/1996/7. Retrieved from UNFCCC:

http://unfccc.int/cop4/resource/docs/1996/agbm/07.htm [Last access: 20.12.2016].

UNFCCC (2000). Tracing the origins of the Kyoto Protocol: An article-by-article textual history. FCCC/TP/2000/2. Retrieved from UNFCCC:

http://unfccc.int/resource/docs/tp/tp0200.htm [Last access: 20.12.2016].

UNFCCC (2015). Adoption of the Paris Agreement. FCCC/CP/2015/L.9. Retrieved from

UNFCCC: https://unfccc.int/resource/docs/2015/cop21/eng/109r01.pdf [Last access:

24.12.2016].

Weiler, F. (2012). Determinants of bargaining success in the climate change negotiations. Climate Policy, 12(5), 552-574.

World Bank (2013). Oil rents, Coal rents, and Gas Rents, 2012. Retrieved from the World Bank: http://databank.worldbank.org/data/reports.aspx?source=world-developmentindicators\#s_c [Last access: 11.01.2017].

World Bank (2016). GDP per capita. Retrieved from: http://data.worldbank.org/indicator/NY.GDP.MKTP.CD [Last access: 24.12.2016].

Young, O. (2014). Does fairness matter in international environmental agreements? Ch. 2 in Cherry, T.L., Hovi, J., \& McEvoy, D.M. (eds.): Toward a new climate agreement: Conflict, resolution and governance. London: Routledge. 


\section{Tables}

\begin{tabular}{|c|c|c|}
\hline Variable name & Operationalisation & Data source \\
\hline Responsibility & $\begin{array}{l}\text { References made to 'Responsibility'/ } \\
\text { total fairness references }\end{array}$ & Content analysis \\
\hline Capability & $\begin{array}{l}\text { References made to 'Capability'/ } \\
\text { total fairness references }\end{array}$ & Content analysis \\
\hline Rights (needs) & $\begin{array}{l}\text { References made to 'Rights (needs)'/ } \\
\text { total fairness references }\end{array}$ & Content analysis \\
\hline Current emissions & Fossil fuel emissions per capita (2013) & Global Carbon Project (2014) \\
\hline $\begin{array}{l}\text { Historical } \\
\text { emissions }\end{array}$ & $\begin{array}{l}\text { Cumulative } \mathrm{CO}_{2} \text { emissions per capita } \\
(1850-1990)\end{array}$ & CAIT (2015) \\
\hline Capacity to pay & $\begin{array}{l}\text { Natural logarithm of GDP per capita } \\
\text { (US\$ 2014) }\end{array}$ & World Bank (2016) \\
\hline Annex I member & $0=$ No, $1=$ Yes & $\begin{array}{l}\text { UN (1992, with amendments } \\
\text { from 1998) }\end{array}$ \\
\hline Vulnerability & ND-GAIN Vulnerability score (2014) & ND-GAIN (2015) \\
\hline
\end{tabular}

Table 1: Independent variables in regression analysis with data sources 


\begin{tabular}{lccccc}
\hline & Responsibility & Capability & Rights (needs) & Sum & $\begin{array}{c}\text { References per } \\
\text { document }\end{array}$ \\
\hline Switzerland & 22 & 23 & 7 & 52 & 17.3 \\
Brazil & 30 & 11 & 8 & 49 & 12.3 \\
China & 26 & 12 & 11 & 49 & 12.3 \\
India & 27 & 8 & 15 & 50 & 10 \\
LMDC & 83 & 13 & 41 & 137 & 9.8 \\
Bolivia & 24 & 11 & 12 & 47 & 9.4 \\
AILAC & 37 & 37 & 10 & 84 & 7.6 \\
Ecuador & 10 & 3 & 7 & 20 & 6.7 \\
Algeria & 18 & 3 & 9 & 30 & 6 \\
Jordan & 11 & 2 & 4 & 17 & 5.7 \\
\hline
\end{tabular}

Table 2: Parties with high frequencies of fairness references (Countries with two or less documents are excluded.)

\begin{tabular}{llll}
\hline & Responsibility & Capability & Rights (needs) \\
\hline Constant & $-4.341^{* *}(1.988)$ & $-4.029^{* *}(1.843)$ & $0.115(1.416)$ \\
GDP/Cap. & $0.751^{*}(0.384)$ & $0.475(0.356) \mathrm{H}_{3}:-$ & $-0.223(0.277)$ \\
Current emissions/Cap. & $-59.983^{* *}(24.080) \mathrm{H}_{1}:-$ & $7.867(22.892)$ & $-13.130(18.660)$ \\
Historical emissions/Cap. & $0.213(0.501) \mathrm{H}_{2}:-$ & $-0.380(0.464)$ & $0.128(0.346)$ \\
Annex I & $-0.236(0.409) \mathrm{H}_{4}:-$ & $1.080^{* * *}(0.387) \mathrm{H}_{5}:+$ & $-0.549^{*}(0.318) \mathrm{H}_{6}:-$ \\
Vulnerability & $4.661^{* *}(1.963) \mathrm{H}_{7}:+$ & $1.855(1.804)$ & $-1.566(1.385)$ \\
\hline Observations & 134 & 134 & 134 \\
$\mathrm{R}^{2}$ & 0.097 & 0.106 & 0.069 \\
Log likelihood & 18.170 & 156.964 & 94.627 \\
\hline
\end{tabular}

Note: Coefficients marked by asterisks are significantly different from zero at the following confidence levels: $*=0.1 ; * *=0.05 ; * * *=0.01$

Table 3: Regression analysis results: Coefficients and (standard deviations). Hypothesised relationships are denoted next to the corresponding coefficients. 